tion that produced, as one might expect, optimistic mumbling. Apart from Daniel Dennett's slovenly chapter (he begins: "Before there was a field called Cognitive Science, I was working in it"), Peter Baumgartner and Sabine Payr have produced a well written book, although it is more amusing than informative. It is interesting to observe the reluctance of the great to change their minds and to note the ways in which their arguments pass one another by.

Stuart Sutherland is in the Laboratory of Experimental Psychology, University of Sussex, Brighton BN1 9QG, UK.

\section{Thought transference}

Ray Monk

Wittgenstein Reads Freud: The Myth of the Unconscious. By Jacques Bouveresse. Princeton University Press: 1995. Pp. 143. £15.95, \$19.95.

PERHAPS the strangest remark Wittgenstein ever made (among, it must be said, some stiff competition) was his comment to his friend Rush Rhees that he considered himself to be a "disciple of Freud". Given that Wittgenstein seems to have read only two or three of Freud's books, that he showed little interest in - and even a certain hostility to - psychoanalysis and that almost all his few recorded comments on Freud's work are sharply and often devastatingly critical, one wonders what he meant. With disciples like this, one feels, who needs detractors?

One searches in vain in Wittgenstein's writings for an extended discussion of Freud's work and influence. His remarks about Freud are, rather, scattered throughout his rather messy corpus: a few paragraphs in Culture and Value (the collection of his "non-philosophical" writings

\section{IMAGE UNAVAILABLE FOR COPYRIGHT REASONS}

Freud: "threadbare straw man". selected and edited by his executors); some allusive comments in the notes of his lectures made by his students; a few remarks in his recorded conversations with his friends Maurice Drury and Oets Bouwsma; and the odd mention of Freud while discussing entirely different subjects in various of his philosophical writings, including Philosophical Grammar and Remarks on the Philosophy of Psychology. If there is a central text it is the "Conversations on Freud" recorded by Rhees and included in Lectures and Conversations published in 1966, but even this amounts only to a few pages of sketchy comments. If one were to gather together every mention of Freud by Wittgenstein and put them all in a book entitled, say, Wittgenstein on Freud, it would be a rather slim volume. (Wittgenstein on Russell, Wittgenstein on Frege, even Wittgenstein on William James, would, by contrast, be enormous.)

What, then, did Wittgenstein mean by describing himself as Freud's disciple? A common approach to this question is to see in Wittgenstein's 'therapeutic' method of philosophy important affinities with the techniques of Freudian psychoanalysis. When this line was taken by A. J. Ayer in an article in the Listener in the 1940s, however, Wittgenstein reacted angrily against it, insisting vehemently that the two were "different techniques". Another approach, and one that has gained increasing favour in recent times, is to emphasize the importance of finding the right metaphor that lies at the heart of both Wittgenstein's work and (on Wittgenstein's understanding of it) Freud's. "It's all excellent similes", Wittgenstein once told a class about Freud's work, echoing the remark he once made summarizing his own contribution to philosophy: "What I invent are new similes".

Jacques Bouveresse, in this meticulously researched and closely argued study, seems curiously unpuzzled by the enigma of Wittgenstein as a 'disciple' of Freud, and apparently satisfied to repeat the standard lines on the subject. His interest, rather, is in presenting Wittgenstein as a particularly trenchant and devastating critic of Freud. In this he follows other distinguished commentators, including Frank Cioffi and Thomas Szasz, and, despite the wealth of scholarship he brings to his task, he adds disappointingly little to what has already been said. His conclusion, for example, that "Freud defends a kind of classical scientific rationalism, while Wittgenstein clearly belongs to quite another order of thought" is by now little more than a commonplace, and his thesis that "the philosopher isn't really dealing with a science, while the mistake of psychoanalysis is essentially to believe that it is one" has been advanced so many times that it needs a more original defence to breathe new life into it.

One might have expected a French

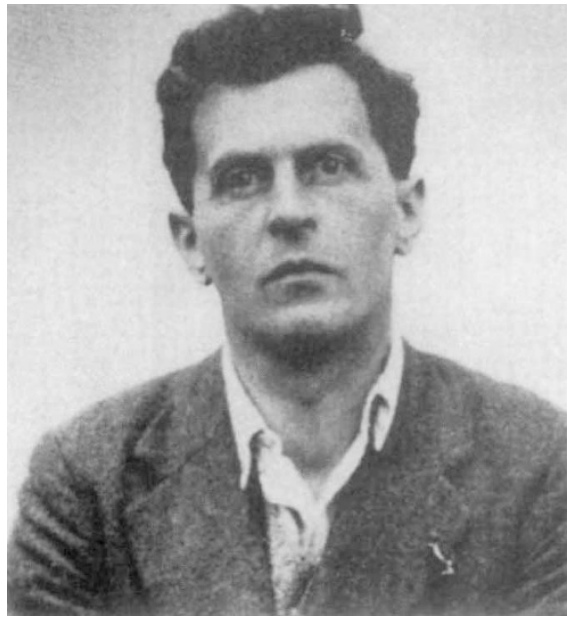

Wittgenstein: "disciple of Freud".

philosopher to try to link Wittgenstein's criticisms of Freud to the use made of Freud's work by leading French thinkers, such as Lacan and Derrida. But Bouveresse self-consciously distances himself from the tradition of thought that prevails in his home country and instead allies himself unreservedly with the opposing Anglo-American analytical tradition, even to the extent of repeating its prejudices against the French ("we French are well known for our tendency to sometimes confuse the practice of philosophy with the practice of free association"). On Lacan, he has a few pages making short work of his notorious notion of the "language of the unconscious", whereas on Derrida he is altogether silent. (Vincent Descombes, on the other hand, devotes most of his foreword to a discussion of Lacan and Wittgenstein.) Most of Boueveresse's references are to leading Anglo-American philosophers-of-mind such as Donald Davidson and Daniel Dennett and to the huge body of Wittgensteinian secondary literature written in English.

To an English reader schooled in the literature, then, the book offers few surprises. Its discussion of the difference between reasons and causes, of "the problem of the reality of the unconscious" and of "the generalizing impulse" of philosophers seem, indeed, almost wearingly familiar, and its criticisms of Freud look - especially in the wake of the recent wave of strident Freud-bashing - like attacks on an increasingly threadbare straw man. Nevertheless, in drawing together most of the remarks made by Wittgenstein on Freud, many of the relevant passages from Freud's work and a good deal of quotation from the secondary literature on the subject, Bouveresse has performed a valuable service for the Wittgenstein scholar.

Ray Monk is in the Department of Philos ophy, University of Southampton, Highfield, Southampton SO9 5NH, UK. 